\title{
Meteorological table
}

\section{Mr. Samuel Veall}

To cite this article: Mr. Samuel Veall (1821) Meteorological table, Philosophical Magazine Series 1, 58:282, 319-320, DOI: 10.1080/14786442108652634

To link to this article: http://dx.doi.org/10.1080/14786442108652634

曲 Published online: 27 Jul 2009.

Submit your article to this journal $\asymp$

Џ Article views: 2

Q View related articles $\asymp$ 
Meteorology.

METEOROLOGICAL JOURNAL KEPT AT BOSTON, LINCOLNSHIRE,

BY MR. SAMUEL VEALI.

[The time of observation, unless otherwise stated, is at 1 P.M.]

\begin{tabular}{|c|c|c|c|c|}
\hline 1821. & $\left\{\begin{array}{l}\text { Age of } \\
\text { the } \\
\text { Moon. }\end{array}\right.$ & $\begin{array}{l}\text { Thermo- } \\
\text { meter. }\end{array}$ & $\begin{array}{l}\text { Baro- } \\
\text { meter. }\end{array}$ & $\begin{array}{c}\text { State of the Weather and Modification } \\
\text { of the Clouds. }\end{array}$ \\
\hline Sept 15 & $\begin{array}{c}\text { DAYS. } \\
20\end{array}$ & $68^{\circ}$ & $20 \cdot 00$ & Cloudy \\
\hline 16 & 21 & $66^{\circ}$ & $29 \cdot 80$ & Ditto-rain A.M. \\
\hline 17 & 22 & $61 \cdot 5$ & $29 \cdot 70$ & Rain \\
\hline 18 & 23 & 68. & $29 \cdot 45$ & Stormy \\
\hline 19 & 24 & $63 \cdot 5$ & $29 \cdot 48$ & Cloudy \\
\hline 20 & 25 & $54 \cdot 5$ & $29 \cdot 60$ & Rain \\
\hline 21 & 26 & $66 \cdot 5$ & $29 \cdot 34$ & Cloudy-rain A.M. \\
\hline 22 & 27 & $64 \cdot 5$ & $29 \cdot 50$ & Fine \\
\hline 83 & 28 & $64 \cdot 5$ & $29 \cdot 34$ & Cloudy-rain A.M. \\
\hline 24 & 29 & $56 \cdot 5$ & $29 \cdot 35$ & Rain \\
\hline 25 & 30 & $60 \cdot 5$ & $29 \cdot 65$ & Cloudy \\
\hline 26 & new & $67 \cdot 5$ & $29 \cdot 55$ & Ditto \\
\hline 27 & 1 & $61^{\circ}$ & $29 \cdot 48$ & Rain-thunder storm in afternoon. \\
\hline 28 & 2 & $63^{\circ}$ & $29 \cdot 58$ & Cloudy - stormy with heavy rain at \\
\hline 29 & 3 & $56 \cdot 5$ & $29 \cdot 10$ & Stormy \\
\hline 30 & 4 & $55^{\circ}$ & $29 \cdot 50$ & Ditto \\
\hline Oct. 1 & 5 & $60 \cdot 5$ & $29 \cdot 25$ & Ditto \\
\hline 2 & 6 & $60^{\circ}$ & $29 \cdot 79$ & Fine \\
\hline 3 & 7 & $66 \cdot 5$ & $29 \cdot 48$ & Ditto \\
\hline 4 & 8 & $62 \cdot$ & $29 \cdot 20$ & Rain \\
\hline 5 & 9 & $53^{*}$ & $29 \cdot 60$ & Fine \\
\hline 6 & 10 & $6 k^{\circ}$ & $29 \cdot 70$ & Cloudy \\
\hline 7 & 11 & 64. & $29 \cdot 70$ & Fine-brisk wind. \\
\hline 8 & 12 & $60^{\circ}$ & $29 \cdot 65$ & Cloudy-rain in the morning. \\
\hline 9 & full & $57 *$ & 30 & Fine \\
\hline 10 & 14 & $59^{\circ}$ & $29 \cdot 80$ & Ditto \\
\hline 11 & 15 & $59 \cdot 5$ & $29 \cdot 45$ & Ditto \\
\hline 12 & 16 & $56^{*}$ & $29 \cdot 65$ & Ditto \\
\hline 13 & 17 & $54 \cdot 5$ & $30 \cdot 12$ & Ditto \\
\hline 14 & 18 & $57^{\circ}$ & $30 \cdot 12$ & Ditto \\
\hline
\end{tabular}


METEOROLOGICAL TABLE,

By Mr. Cary, of the Strand.

\begin{tabular}{|c|c|c|c|c|c|c|}
\hline \multirow{2}{*}{\multicolumn{2}{|c|}{$\begin{array}{l}\text { Days of } \\
\text { Month. } \\
\mathbf{1 8 2 1} \text {. }\end{array}$}} & \multicolumn{3}{|c|}{ Thermometer. } & \multirow[b]{2}{*}{$\begin{array}{l}\text { Height of } \\
\text { the Barom. } \\
\text { Inches. }\end{array}$} & \multirow[b]{2}{*}{ Weather. } \\
\hline & & \multirow{3}{*}{ 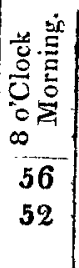 } & \multirow{3}{*}{ 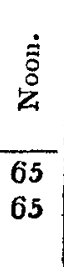 } & \multirow{3}{*}{ 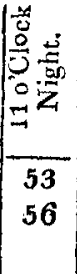 } & & \\
\hline Sept. & 27 & & & & $29 \cdot 94$ & Showery \\
\hline & 28 & & & & .88 & $\begin{array}{l}\text { Fair with high } \\
\text { wind. }\end{array}$ \\
\hline & 29 & 56 & 59 & 49 & $\cdot 57$ & Cloudy with do. \\
\hline & 30 & 47 & 59 & 59 & $\cdot 92$ & Fair \\
\hline \multirow{26}{*}{ Oct. } & 1 & 60 & 65 & 52 & $\cdot 74$ & Fair \\
\hline & 2 & 52 & 59 & 56 & $30 \cdot 20$ & Fair \\
\hline & 3 & 60 & 65 & 62 & $29 \cdot 90$ & Showery \\
\hline & 4 & 62 & 62 & 60 & .60 & Rain \\
\hline & 5 & 47 & 58 & 47 & .99 & Fair \\
\hline & 6 & 50 & 64 & 52 & 30.09 & Fair \\
\hline & 7 & 56 & 65 & 57 & .08 & Fair \\
\hline & 8 & 57 & 61 & 50 & .05 & Showery \\
\hline & 9 & 45 & 59 & 49 & $\cdot 35$ & Fair \\
\hline & 10 & 47 & 61 & 50 & .09 & Fair \\
\hline & 11 & 49 & 55 & 49 & $29 \cdot 74$ & Cloudy \\
\hline & 12 & 50 & 57 & 49 & $\cdot 95$ & Fair \\
\hline & 13 & 46 & 58 & 48 & $30 \cdot 39$ & Fair \\
\hline & 14 & 44 & 59 & 50 & .39 & Fair \\
\hline & 15 & 46 & 52 & 44 & $\cdot 31$ & Showery \\
\hline & 16 & 42 & 52 & 48 & 21 & Fair \\
\hline & 17 & 46 & 52 & 50 & $\cdot 18$ & Fair \\
\hline & 18 & 50 & 59 & 50 & $29 \cdot 98$ & Cloudy \\
\hline & 19 & 51 & 53 & 50 & 86 & Cloudy \\
\hline & 20 & 51 & 53 & 43 & .02 & Stormy \\
\hline & 21 & 41 & 53 & 46 & .20 & Fair \\
\hline & 22 & 45 & 54 & 45 & $\cdot 27$ & Fair \\
\hline & 93 & 49 & 52 & 48 & .29 & Rain \\
\hline & 24 & 46 & 52 & 44 & $\cdot 54$ & Cloudy \\
\hline & 25 & 46 & 53 & 51 & 30.00 & Cloudy \\
\hline & 26 & 51 & 59 & 54 & $\cdot 11$ & Cloudy \\
\hline
\end{tabular}

N.B. The Barometer's height is taken at one o'clock.

Observations for Correspondent who observed the

8th Oct: 8 o'Clock M. Barom. 29.994 Ther. attached $63^{\circ}$ Detached 57

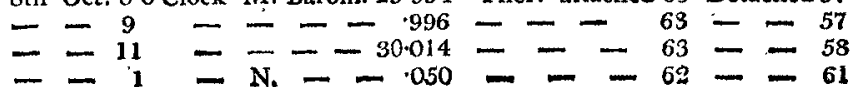

